\title{
BIM技术在公路设计中的应用与实践研究
}

\author{
陈彦君* \\ 内蒙古交通设计研究院有限责任公司, 内蒙古 010010
}

摘 要: 所谓BIM技术, 是一种应用于工程设计、建造、管理的数据化工具。在信息技术快速发展的当下, BIM (建筑信息模型) 技术在公路设计与施工中得到了更加广泛地应用, 并在提升公路设计水平等方面发挥了至关重要的 作用。在本研究中, 将针对BIM技术的特点及其在公路设计中的应用进行重点研究。通过本研究, 希望能够进一步强 化BIM技术在公路设计中的应用水平。

关键词: BIM技术; 公路设计; 应用现状

一、引言

所谓BIM技术, 即建筑信息模型技术。这一概念最早在美国被提出和应用。而在我国, BIM技术的引进和应用时 间已经超过 10 年。在很多大型工程的设计和施工中, 还技术都得到了比较广泛地应用 ${ }^{[1]}$ 。在这一前提下, 针对该技术 在公路施工中的应用情况与实际应用措施进行研究就具备了重要的意义。在本文中, 将对BIM技术的特点、在公路设 计中的应用现状和加强该技术应用水平的措施进行重点研究。

\section{二、BIM 技术的特点}

与传统的工程设计与施工技术相比, BIM技术具有可视化、协调性、模拟性、优化性和造价精准性等特点。在这 些特点的影响下, 一方面, 由于应用了 BIM技术进行工程设计和施工, 我国公路施工企业的设计与施工水平都得到了 显著提升。另一方面, 在应用BIM技术之后, 设计与施工人员能够更加直观的发现工程项目设计和施工中存在的问题 并加以解决。可以说，这些特点为BIM技术的广泛应用提供了有力的基础保障。

\section{(一) 可视化}

BIM技术在实际应用中的最主要功能之一就是构建建筑的三维模型。在相当长的时间内, 建筑工程的设计图纸都 是二维图纸。而BIM技术的应用, 实现了设计图纸的立体化和三维化, 并在这一基础上构建可视化的建筑三维立体模 型。与传统的二维图纸相比, 依托BIM技术构建的三维模型在可视化这一特征方面处于更高的水平。在当下, 随着工 程建设技术水平的不断提升, 各种类型的工程建设工作在设计方案和设计思路方面变得愈发复杂。因此, 具有可视化 特点的BIM技术的应用价值也得到了更大幅度地提升。例如, 在进行公路工程设计的过程中, 利用BIM技术可以生成 精确的桥梁和隧道构造图, 并在这一基础上进行施工 ${ }^{[2]}$ 。如图1所示, 图1中的三维立体图像为某公路桥梁桥墩部位。

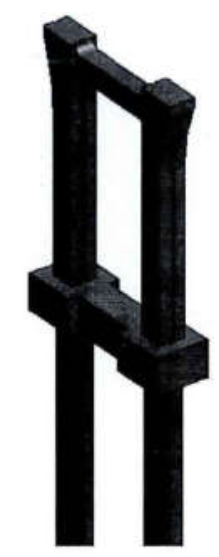

图1 某公路桥桥墩三维立体设计图

*通讯作者: 陈彦君, 1985 年3月, 男, 汉族, 内蒙古武川人, 就职于内蒙古交通设计研究院有限责任公司, 高级 工程师, 硕士研究生。研究方向: 公路工程。 


\section{（二）协调性}

在公路工程设计过程中, 需要应用建筑学、结构学和机电专业的相关知识与人员。而在这相当长的一段时间内, 公路工程设计中上述各个不同系统之间的协调水平一直无法得到大幅度提升。而在应用BIM技术之后, 这一问题得到 了很好地解决。之所以如此, 最主要的原因就是该技术具有非常好的协调性, 能够在工程设计和施工过程中对各个不 同部门和系统之间的工作进行有效地协调，从而保障工程设计与施工的顺利进行。同时，在具备良好协调性的基础 上，BIM技术的应用，也使得公路项目建设过程中公路主体结构与附属设施的配套性得到了更大程度地提升 ${ }^{[3]}$ 。

（三）模拟性

在进行公路工程设计和施工的过程中, BIM技术中的相关软件不仅能够快速建立三维立体模型，而且能够通过模 拟动画的形式模拟出项目施工的各个步骤。在这一基础上，三维模型就变为模拟化的四维模型。同时，BIM技术还能 够对原材料进场、施工中的劳动力分配等活动进行事前模拟, 并在这一基础上对事先制定好的施工方案进行更加科学 的优化与创新, 进一步提升施工的效率和质量。例如, 在图 2 中, 就是针对公路桥梁施工过程进行的模拟。通过观察 可以看出, 该图面是某公路施工中路面铺设步骤的四维施工模拟图。可以说, 正是由于具备了模拟性这一特点, 导致 BIM技术在公路工程设计和施工中具有了更大的应用价值。

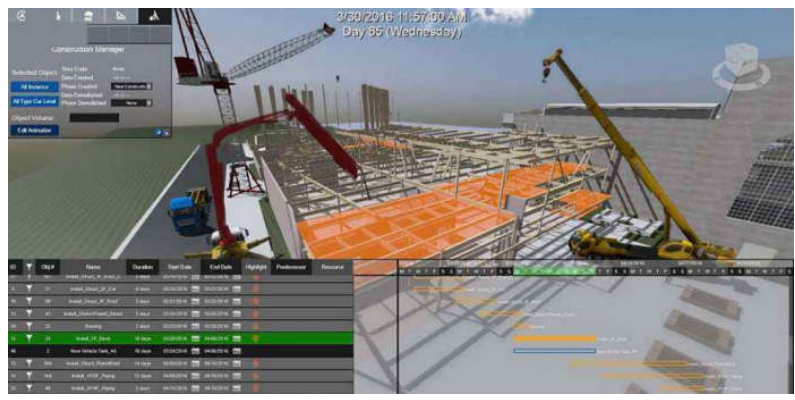

图2 某公路施工四维施工模拟图

（四）优化性

在经济和科学技术快速发展的当下, 公路项目的设计和施工工作变得愈发复杂。因此, 单独依靠施工设计人员自 身的素质难以保障设计和施工方案的尽善尽美。而在应用BIM技术之后，该技术能够利用相关的计算机软件和模拟技 术一次生成多个施工方案, 便于设计者和施工单位进行更加全面的对比和选择。从这一角度来看, BIM技术具有非常 好的优化性特点。

（五）造价精确性

BIM技术的核心就是将各个构件的相关数据信息形成可视化的参数，并在这一基础上通过对构件进行模拟化的拉 伸、旋转等操作, 能够对各个构件的结构和对质量的要求进行更加全面地了解, 并在这一基础上通过对采购方案进行 优化达到对采购成本与工程造价进行精确控制的目标 ${ }^{[4]}$ 。可以说, 这一特点对BIM技术的应用于推广起到了相当大的 促进作用。

\section{三、公路设计中常用的 BIM 技术应用平台}

在科学技术飞速发展的当下，只依靠一类软件进行BIM技术的运用已经无法满足公路工程设计的需求。因此， 各种以BIM技术为基础的新型计算机软件开始面世和应用，并成为BIM技术的重要应用平台。在本文中，将针对 Autodesk、Bentley、Nemetschek、Dassault几种BIM技术应用平台进行简要的介绍。

\section{(一) Autodesk}

Autodesk软件是由Autodesk公司研发和设计的一款设计软件。该软件依托BIM技术设计, 能够实现对设计方案和 图纸的三维立体建模, 并在这一基础上提升工程设计的速度与质量。与其他软件相比, 该软件的最主要优势之一就是 操作简单。同时, 由于软件中拥有第三方开发的内容, 因而工程设计者能够在进行项目设计的过程中查看和参考成功 的工程项目设计方案对自身的设计方案进行进一步优化和完善。因此, 现阶段Autodesk软件在公路工程设计中的应用 比较广泛。

\section{(二) Bentley}


在BIM设计软件中, Bentley公司研发的主要用于设计公路、桥梁、机场、大厦等大型工程建设项目。在该软件系 统中, 拥有很多系统自带的BIM模型。由于公路、桥梁等大型工程项目的设计具有很多共同特点, 因而设计人员只需 要针对系统自带的类似模型进行改变和创新就能够完成工程项目设计工作。可以说, 该软件的应用能够大幅度减少设 计人员的工作量，从而实现设计工作效率和质量的进一步提升。

\section{(三) Nemetschek}

在软件中应用BIM技术最早开始于Nemetschek公司。通过将BIM技术融人软件之中, Nemetschek公司开发了多款 用于工程设计的软件, 并在工程项目设计与建设过程中得到了比较广泛地应用。但是由于该软件平台中的系统功能与 我国大多数工程项目建设企业使用的设计软件并不匹配, 导致Nemetschek软件在我国的应用范围相对比较有限。在当 下，该软件在欧美国家的大型工程设计中应用比较广泛。

( 四) Dassault

法国Dassault公司针对大型工程设计中BIM技术的应用方式也进行了深人研究, 并在这一基础上开发了多款工程 项目设计软件。与其他类型的软件相比, Dassault设计的软件更加适用于对大型建筑工程进行设计。例如, 我国的北 京奥运会主会场鸟巢就是在Dassault公司研发的多款设计软件的支持下设计和施工的。而在公路工程设计和施工中， 该软件技术的应用相对较少。

\section{四、BIM 技术在公路设计中的应用}

通过以上研究可以发现, 在当下, BIM技术在建筑和公路设计施工中都得到了比较广泛地应用。由于该技术具有 可视化、协调化等特点, 因而其大范围的应用促进了建筑和公路施工设计水平的进一步提升。但是必须看到，在公路 设计和施工中应用BIM技术，也逐渐暴露出了一些问题。因此，需要制定更加科学的措施促进BIM技术研发与应用水 平的进一步提升。在本文中，将针对该技术的应用现状、面临的实际问题和解决措施进行全面研究。

(一) 应用现状

在我国，为通过交谈建设进一步刺激经济发展，我国政府部门和相关企业在道路交通设施建设方面投人了相当大 的精力和海量的资金。在这一基础上, BIM技术的应用也变得愈发频繁。由于BIM具有可视化、协调性等特征，因而 能够在设计和施工方案的制定过程中发挥出非常大的作用 ${ }^{[5]}$ 。

众所周知, 在当下, 我国很多公路施工企业的设计方案仍然停留在平面图纸阶段, 设计人员在这一基础上进行 设计，并在对现场进行考察之后对设计方案进行调整。但是在BIM技术模式下，已经可以事先设计图纸的三维立体建 模。在这一基础上，越来越多的施工企业开始在工程设计阶段应用BIM技术，并希望通过该技术的应用实现设计工作 效率与质量的进一步提升。例如在图3中，某公路项目设计中应用了BIM技术进行了三维立体建模。通过图3可以发 现, 在三维立体模型中, 公路的周边环境、设计路线等信息都得到了比较直观的反应, 因而能够帮助设计者对设计方 案进行更加科学的优化和完善 ${ }^{[6]}$ 。

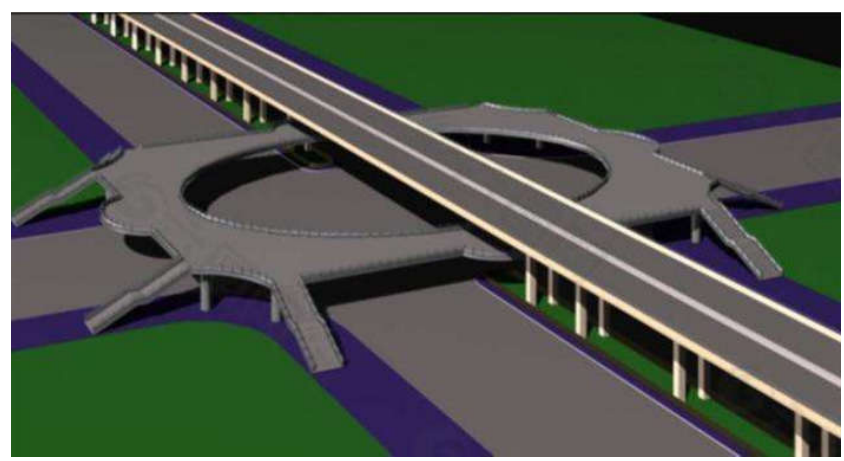

图3 某公路项目三维立体模型

在将使用BIM技术生成的路线模型与地形模型结合之后, 能够非常直观的发现新建公路工程与原有地形地貌之间 的交互关系。在这一基础上, 设计人员能够提出更加科学的设计方案，并通过设计和构建桥梁、隧道的方式实现工程 施工效率与施工质量的进一步提升。之后，还能够应用BIM技术生成更加精确的施工效果图。

（二）遇到的困难 
在将BIM技术应用于公路项目设计和施工的过程中, 也逐渐出现了一些需要解决的问题。其中, 最主要的问题之 一就是现有的BIM技术更加适用于建筑设计和施工。由于公路设计施工与建筑的设计施工存在较大差异, 因而导致 BIM技术在公路项目设计中无法达到最佳的应用效果。在具体表现方面, 建筑施工设计中有比较集中的设计主体, 因 而能够轻松做到设计和施工的标准化。而在公路设计和施工中, 应用BIM技术实现标准化的难度则相对较大, 因而导 致其对公路设计和施工效率的提升无法发挥最大的促进作用。同时, 由于公路施工需要面对复杂的路况和地形，因而 对公路设计BIM技术进行标准化处理的技术难度比较大。在当下, 无论国内外的软件开发企业在这一方面都没有形成 能够实际应用的研究成果 ${ }^{[7]}$ 。

\section{（三）解决措施}

鉴于BIM应用于公路项目设计时存在的现实困难，需要采取科学的措施加以应对和解决。在具体措施方面:

虽然现阶段BIM技术在公路设计中无法达到最佳应用效果，但与传统的设计技术相比仍然具有无可比拟的技术优 势。因此, 需要公路施工企业在现有的基础上进一步增加BIM技术的应用范围, 并在这一前提下对BIM技术应用过程 中形成的经验和教训进行总结, 为BIM技术的进一步升级提供更多能够借鉴的实践经验。这一措施不仅能够帮助施工 企业提升自身的设计与施工水平, 而且能够帮助软件研发企业和相关部门进一步加快BIM技术的研发与升级进程, 从 而为该技术在公路设计中的应用提供基础保障。

我国各大高校需要进一步加大培养BIM技术开发与应用人才的力度, 通过在高校中增加相关专业和引进国外先进 研究成果等方式提升自身的教育水平, 培养出更多的BIM技术开发与应用人才。在这一基础上, 我国的BIM技术研发 与应用水平就能够得到更进一步的提升 ${ }^{[8]}$ 。

\section{五、结论}

综上所述, 在公路设计与施工中, BIM技术的应用不仅能够促进设计与施工水平的进一步提升, 而且能够帮助公 路施工企业进一步加强自身的设计与施工质量。但是在当下, 由于BIM技术并非专门用于公路设计的技术, 因而其实 际应用效果还存在一定的提升空间。在本研究中, 针对这一问题进行了详细的分析, 并为其制定了解决方案。通过本 研究，希望能够帮助公路施工企业进一步强化BIM技术的实际应用水平，实现我国公路建设水平的进一步提升。

\section{参考文献:}

[1]陈志,杨艳群,杨秀靖,林君君,杨轶涁, 陈倬.BIM技术在公路改扩建工程交通导改中的应用 [J]. 交通工程, 2019,19(05):6-10.

[2]赵玉石.BIM技术在高速公路工程建设中应用[J].交通世界, 2019,14(27):144-145.

[3]丁瑞锋,王绥庆.BIM技术在公路设计中的应用与展望[J].城市建设理论研究(电子版), 2019,11(07):83.

[4]李金龙,王欣南,陈中治,望开潘.BIM技术在公路桥梁设计中的应用浅析[J]. 低温建筑技术, 2019,41(02):67-69.

[5]张万庭.基于BIM技术的公路路线设计分析 [J].人民交通, 2018,15(09):60-61.

[6]何晓君.BIM技术在公路设计中的应用价值研究[J].公路交通科技(应用技术版), 2018,14(08):85-87.

[7]高子尧.长韶娄高速公路起点段线形方案比选及BIM技术应用[D].长沙理工大学, 2017.

[8]严丽娟.建筑信息模型 (BIM) 在高速公路项目管理中的应用研究[D].长江大学, 2016. 